Classification

Physics Abstracts

$81.90+\mathrm{c}-07.75+\mathrm{h}-07.80+\mathrm{h}$

\title{
Microanalytical Characterization of Art-Work Materials: Spatially Resolved Techniques
}

\author{
Enrico Ciliberto $\left({ }^{1}\right)$, Ignazio Fragalà $\left({ }^{1}\right)$, Nunzio Antonio Mancini $\left({ }^{2}\right)$ and Giuseppe Spoto $\left({ }^{1}\right)$ \\ ( $\left.{ }^{1}\right)$ Dipartimento di Scienze Chimiche, Università di Catania, V. le A. Doria 6, 95125 Catania, Italy \\ $\left({ }^{2}\right)$ Centro Universitario di Microscopia Elettronica CUMEC, Dipartimento di Fisica, Università di \\ Catania, V. le A. Doria 6, 95125 Catania, Italy
}

(Received March 1; accepted June 19, 1995)

\begin{abstract}
This study presents the application of lateral (SEM/EDX, SAM, SIMS) and vertical (SAM, XPS, SIMS) high resolution techniques on materials in art- work of cultural heritage. Emphasis will be placed on how such techniques are now indispensable in a science-based approach to the characterization of materials and the rationalization of their degradation, this in itself being essential for conservation and useful for a clearer understanding of the artistic techniques used in the past.
\end{abstract}

\section{Introduction}

The last few decades have seen the development of a number of techniques providing spatiallyresolved microanalytical information. These techniques, based on widely differing physical phenomenologies, have led to new routes of exploration in the materials sector. In the field of artmaterials of the past and work of cultural heritage in general these techniques have opened up new diagnostic approaches. From among the many techniques of this nature we have chosen to concentrate on those with which we are more familiar, in particular, Scanning Electron Microscopy (SEM) with its associated techniques: the analysis of $X$ radiation following electron impact on the material under examination (Energy-Dispersive X-ray Spectrometer, EDX); Scanning Auger Microscopy (SAM), already widely in use in the study of metals; and lastly, X-ray Photoelectron Spectroscopy (XPS) and Secondary Ion Mass Spectrometry (SIMS), applied in those cases which clearly demonstrate how these are particularly applicable as surface techniques. The use of these techniques, whether with lateral (SEM/EDX, SAM, SIMS) or vertical (SAM, XPS, SIMS) high resolution does not only present a means of obtaining the required data as a function of spatial coordinates, but clearly permits the characterization of microscopic amounts of material, thus minimizing damage to the object under examination. 


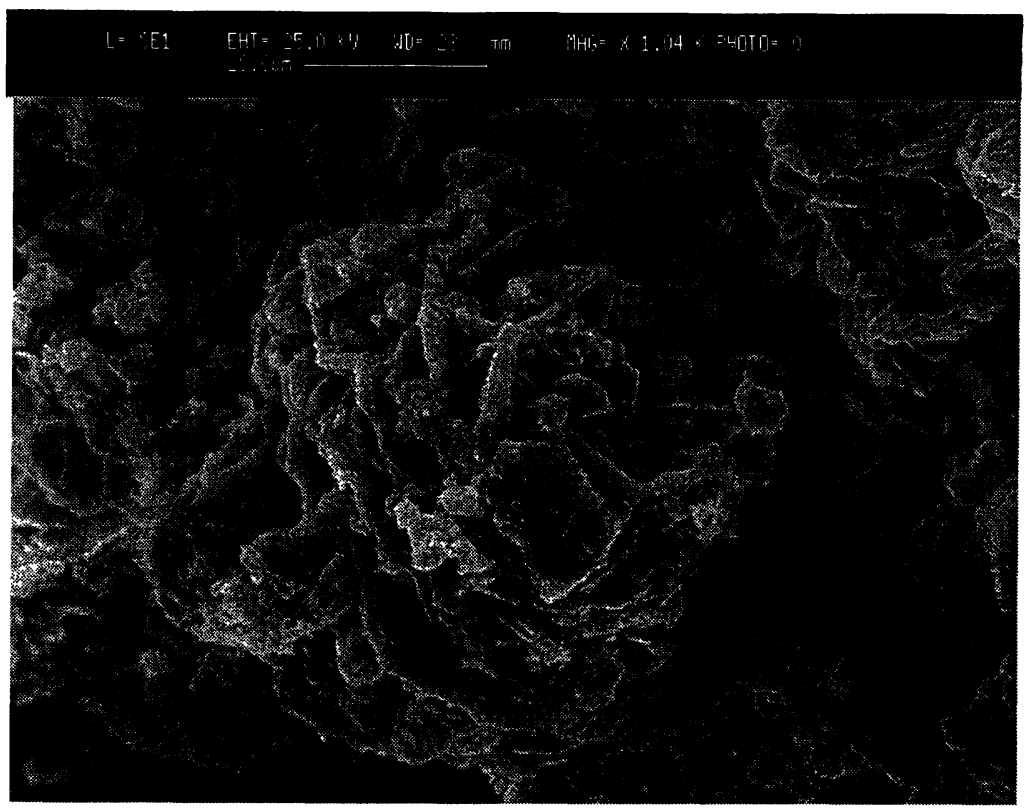

Fig. 1. - Surface secondary electron image of a limestone coming from the S. Benedetto church (Catania) facade. The crust is formed by a network of gypsum crystals.

\section{Electron Bombardment Techniques}

An area of investigation, perhaps one of the most important, involves the physical phenomenologies resulting from the bombardment of material with a suitably collimated electron beam. SEM, in particular, is already widely used in the study of materials and it would appear superfluous to outline its theoretical principals in the context of this paper [1,2]. It would, however, seem appropriate to provide a number of examples showing how this technique can be fully exploited in art heritage sector.

The technique may be applied to extremely small samples and often no specific preparation is necessary [3], (such as obtaining ultra-thin sections of material which must then be polished), thus guaranteeing the indestructibility of the artifact being studied. When working on insulator such as glass, ceramics, stone or paint-layers it is often advisable to coat the sample with a film of a conductor such as graphite to prevent charging phenomena and to improve the quality of the images. This is especially valid when working in the context of high emission current or high kinetic energy. The images thus obtained are frequently relevant for increasing our knowledge of materials and their degradation. In Figure 1 a magnified image of the external surface of a black crust taken from the calcareous facade of an important monuments of the historic centre of Catania (San Benedetto Church) is shown. The evident characteristic network of gypsum crystals [4,5] testifies the typical degradation mechanisms of rock materials exposed in an urban environment [6].

This technique may provide important information as far as the microscopical images are indicative of the technique used by the artist. In Figure 2, which is a magnified image of a gilded 


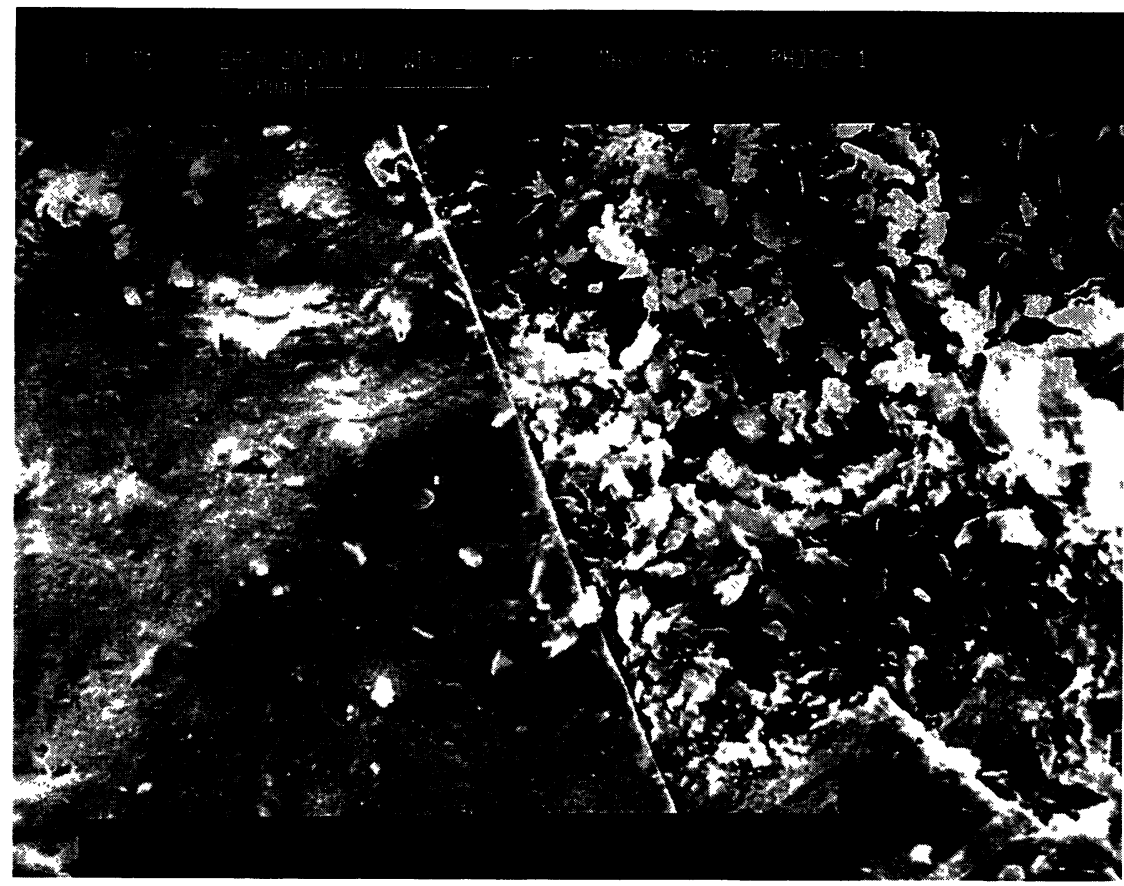

Fig. 2. - Renaissance gilding technology: secondary electron image showing the gold-leaf coating an Armenian Bole substrate.

area on a sculpture, it is easy to identify a gold leaf which is typical of certain gilding methodologies $[7,13]$. In a previous work we have demonstrated that similar images allow us to identify the techniques used by the artist [7] with ease, the thickness of the laminae used and the absence or the presence of restoration work [8].

The recording of backscattered electrons following electron bombardment provides additional information $[1,9]$. Since the probability of backscattering depends on the dimension (i.e. on the atomic number $Z$ ) of the atomic species constituting the surface of the material, it is clear that the images thus obtained provide information of a specifically "chemical" nature. This is clear if we look at Figure 3 which shows the backscattering image of a renaissance paint-fragment. A white area characterized by the presence of atomic species with a high atomic number is immediately evident. This specific case concerns "white lead" (lead basic carbonate) which was often used up until the end of $19^{\text {th }}$ century to lighten the shade of the principal pigments used. It is this that caused the typical surface blackening in the paint layers, induced by the formation of $\mathrm{PbO}_{2}$ or $\mathrm{PbS}$ according to the red-ox potential on the surface induced by different climatic or pollution factors.

Support can be provided by recording the $\mathrm{X}$ radiation emitted following ionization phenomena caused by electronic shell of the atoms making up the material relaxing [10,11]. By determining these emissions, typical in their multiplicity and energy, important qualitative and quantitative chemical analyses can be carried out [12]. It would seem opportune at this point to remember that the area under analysis is not strictly limited to the area of material in contact with the electron beam [1]. This must be taken into account each time spot analyses are carried out on extremely small details of material. In the case of extremely heterogeneous materials it is also necessary to remember that the areas being analysed, even when examined using electron raster on the 


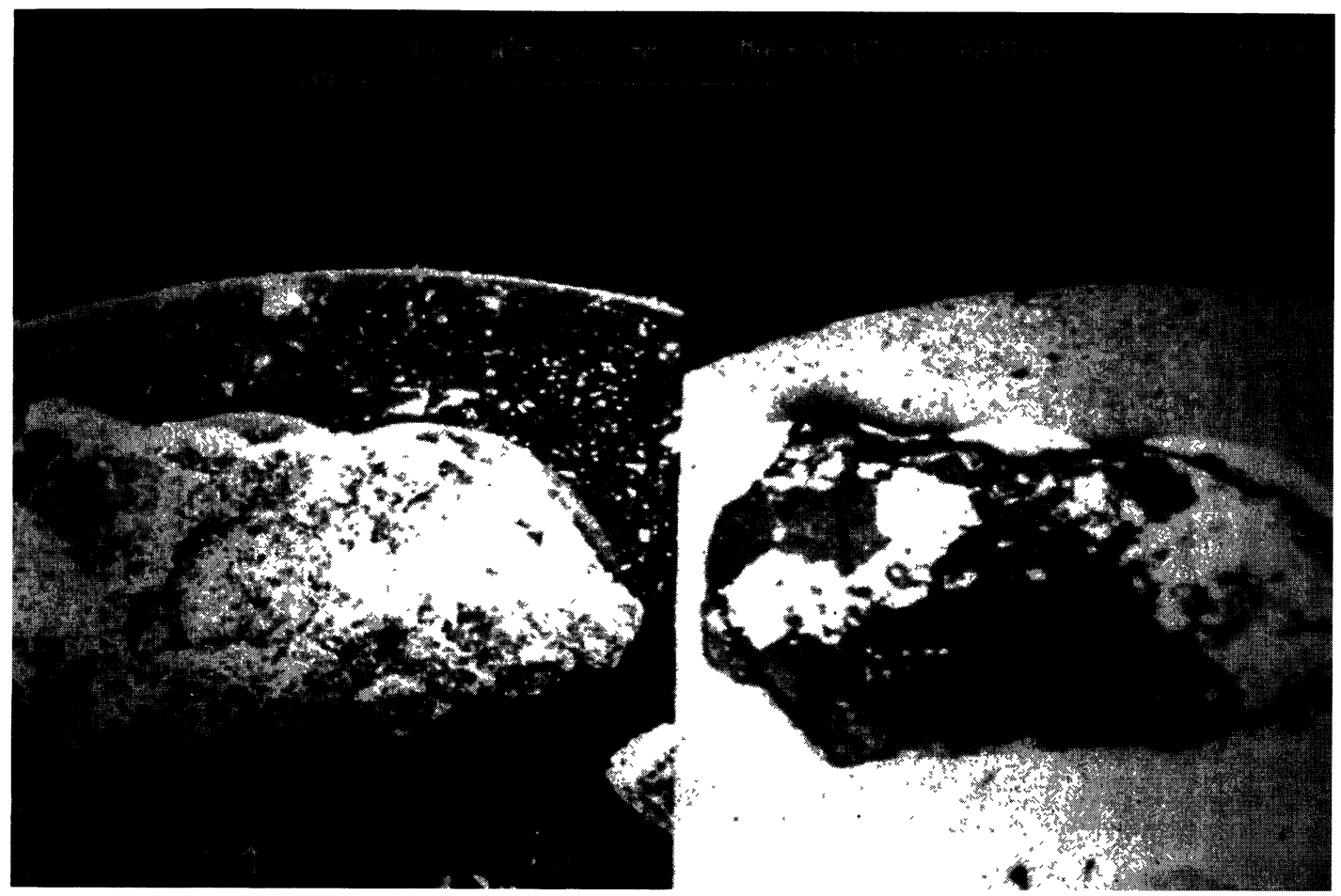

Fig. 3. - Secondary electron image (left) and backscattered electron image (right) of a renaissance "white lead" based pigment.

surface of the material, may not be significant in the overall description of the piece under study. Despite of these apparent limitations the techniques used in the context of this phenomenology, in particular EDX, are still of undeniable and irreplaceable value.

In the case of pigment identification, for example, simple EDX analyses can provide the immediate solution to many fundamental problem. The majority of pigments used in the past were generally of an inorganic nature [7,13] and the identification of the anionic and cationic species present in the pigment leads to the deduction of the nature of the pigment itself with a certain degree of confidence. Figure 4 shows the EDX spectrum of a fragment of red pigment. The presence of lines $\mathrm{M}_{\alpha}, \mathrm{L}_{\alpha}$ and $\mathrm{K}_{\alpha}$, mercury and sulphur respectively, leads to the easy identification of cinnabar, a red mineral pigment used as far back as ancient times, especially in Roman frescoes (known as Pompei Red).

During the atomic relaxation following ionization, Auger electrons may be emitted whose kinetic energy is not dependent on the incident electrons. This is instead related solely to the energy of three shells belonging to the atomic species where relaxation occurs [14]. The kinetic energies of Auger electrons are typical for each of the various chemical elements and are thus a valuable means of analysis. It is necessary to pause at this point to make some general observations. The fact that information is conveyed by charged particles makes this procedure especially susceptible to the charging effects which are inevitably present in insulators [15-17], in spite of this some applications on non conducting materials have been reported as for example the case of the dating of manuscript inks [18]. The electron escape depth from the material is limited (a few tenths 


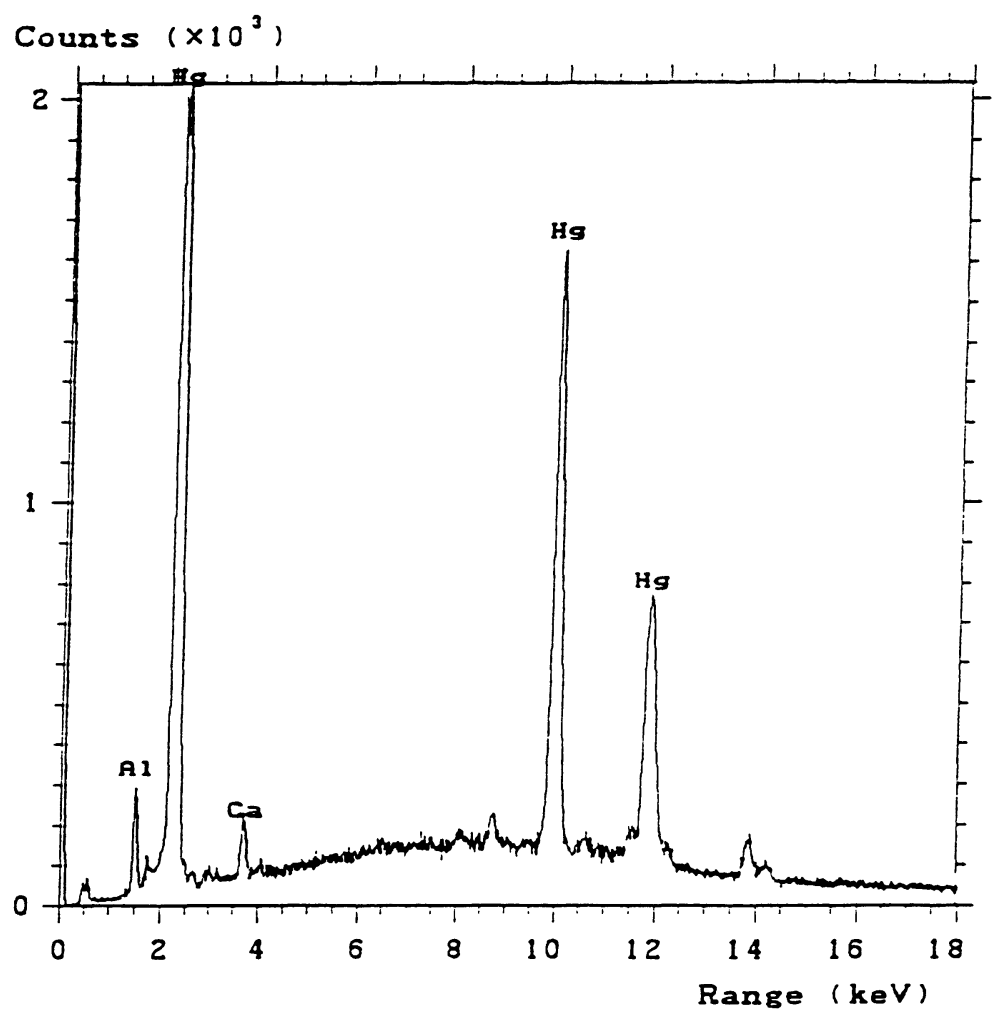

Fig. 4. - EDX spectrum of a "Red Pompei" (cinnabar) $1 \mu \mathrm{m}$ particle. The $\mathrm{Hg} \mathrm{M}_{\alpha}$ and S $\mathrm{K}_{\alpha}$ lines are not resolved in the graph. They are detectable in the expanded spectrum.

of Angstroms) meaning that the chemical information concerns the first few monolayers on the surface of the material [19]. Through the appropriate selection of the Auger electrons generated through the involvement of the valence shells it is also possible to obtain information concerning the element's oxidation state or at least ascertain its chemical environment. Besides this, by constructing two-dimensional matrices where elements $I_{i j}$ are proportional to the intensity of a specific family of Auger electrons and indices $i, j$ are in relation to spatial coordinates $x, y$ of the point under analysis, it is possible to build up chemical distribution maps (SAM technique). These considerations render the Auger technique esperially useful when it is necessary to investigate the surface or intergranular aspects of metals such as iron alloys, bronze etc... [20-23]. Figure 5 shows the Auger signals at $\sim 50 \mathrm{eV}$ of iron which correspond to a metallic area and an oxidized area formed following a lesion caused by mechanical stress during the process of hammering in a square nail. The sample comes from the $16^{\text {th }}$ century wooden ceiling of the Cathedral of Assoro in Sicily. An energy shift is clearly evident and may be ascribed to different chemical states in the iron. Figure 6 provides two SAM maps showing the Fe LMM and O KLL signals adjacent to the corresponding SEM image where we can see the mechanical stress line. The oxidation area of the iron clearly correspond to the area of stress. This allows us to deduce that certain defects closely connected to execution techniques and material processing can heavily influence degradation mechanisms in the materials concerned. 

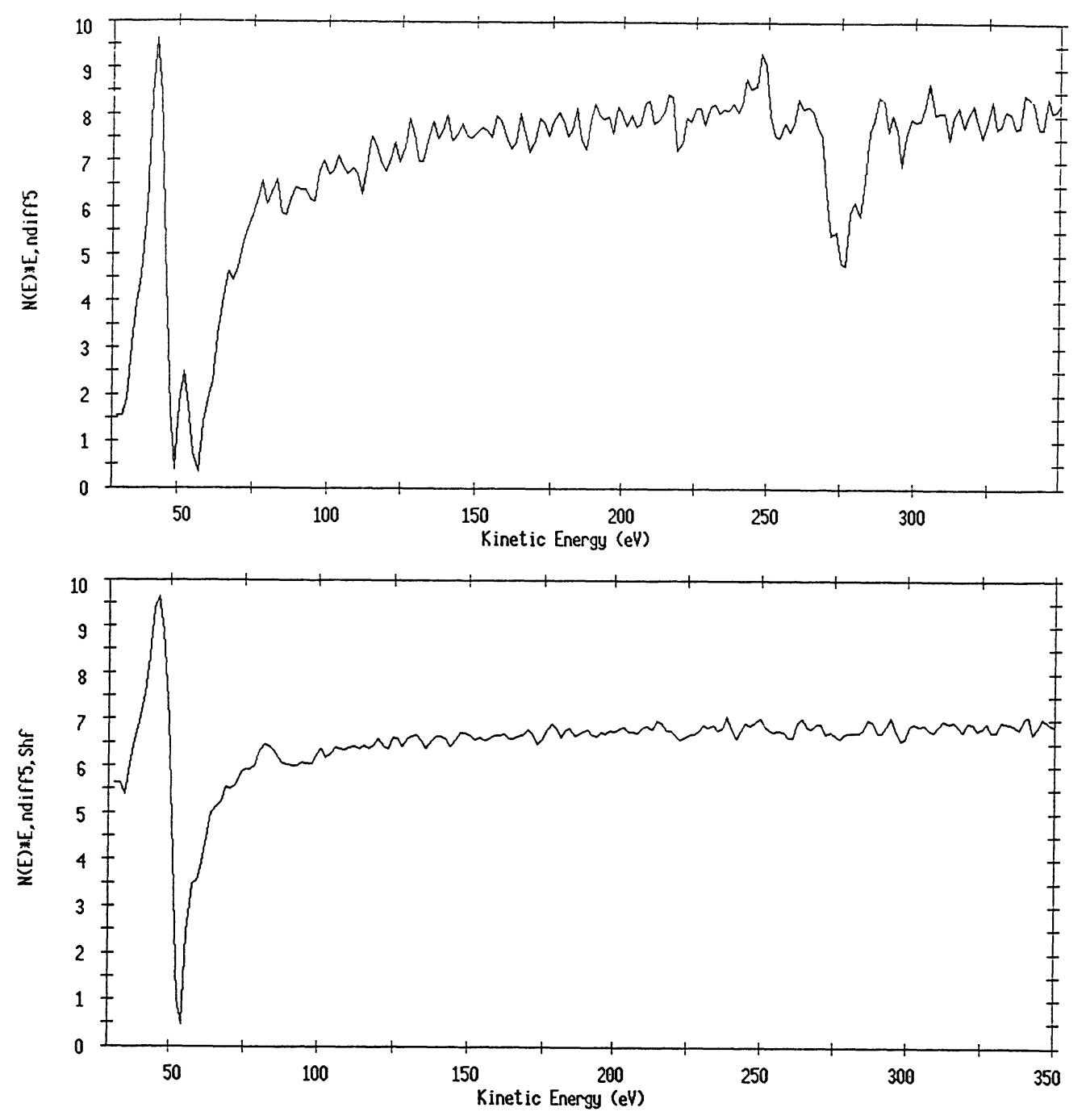

Fig. 5. - AES spectra obtained from the oxidized (upper) and not oxidized regions of a Renaissance nail.

\section{X-Ray Photoelectron Spectroscopy}

Techniques related to the bombardment of a material with X-ray photons are of great importance. Of those used, X-ray photoelectron spectroscopy (XPS) is of particular relevance for the quantity of information it provides $[14,22]$. Orbital binding energies that are typically correlated to various types of atoms show similarly typical chemical shifts which can often lead to the identification of the chemical environment of the photoionised element concerned. As in the previous case, with XPS the electronic escape depth is limited, thus making it possible to investigate the interface areas of the material alone. This technique is therefore extremely important for surface investigation and in the field of art materials it allows the study of degradation mechanisms occurring on the surface-atmosphere interface $[8,24,25]$. As an example Figures 7 a,b shows the XPS spectra of the limestone surface of the sample of Figure 1. The investigation of the C1s and 


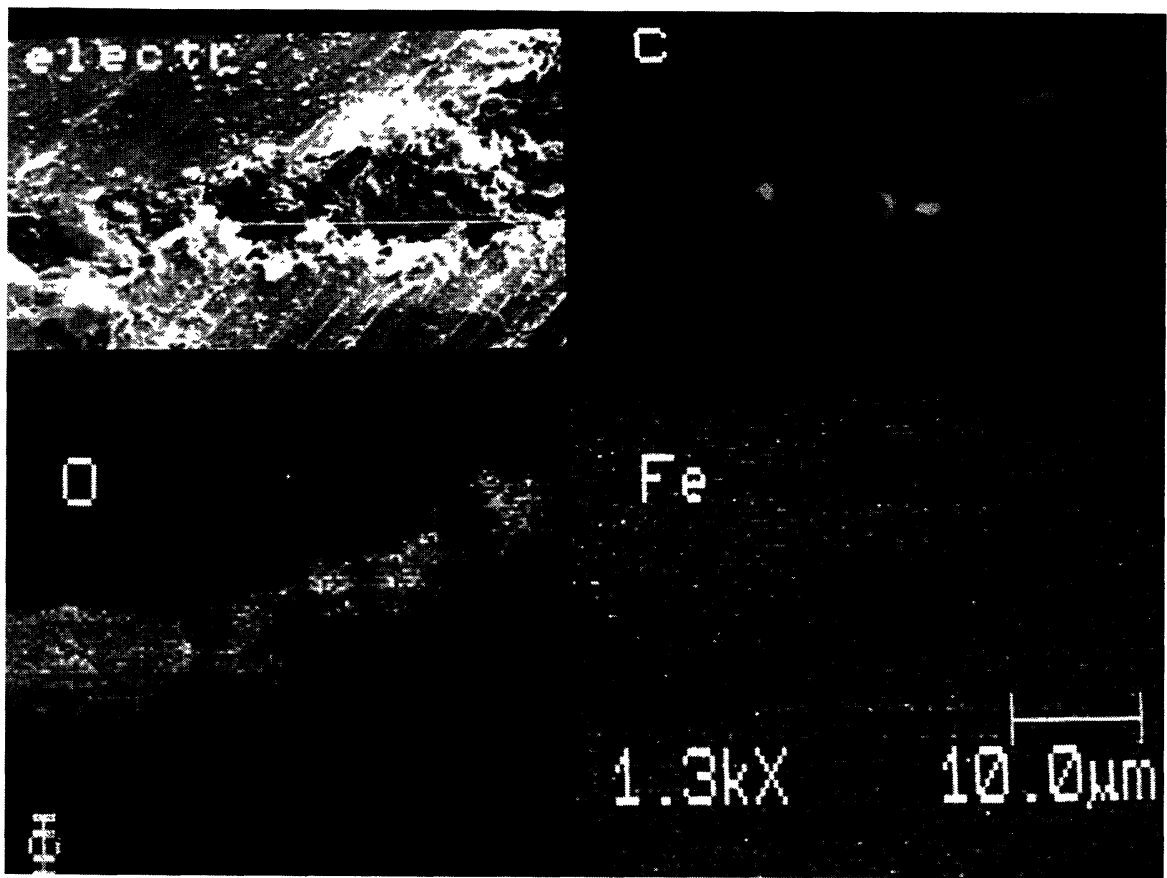

Fig. 6. - Fe, O, C Auger maps and secondary electron image of a stress line in a Renaissance nail: it is evident that the stressed region suffered an iron oxidation.

$\mathrm{N} 1 \mathrm{~s}$ ionization regions provide interesting information about organic and/or biological attack at the interface stone-atmosphere. In the $\mathrm{C} 1 \mathrm{~s}$ region three ionization events centred at $285.0 \mathrm{eV}$, $287.2 \mathrm{eV}$ and $289.3 \mathrm{eV}$ were detected, while two N1s signals were found at $399.6 \mathrm{eV}$ and $402.0 \mathrm{eV}$.

The carbon bands centred at $285.0 \mathrm{eV}$ and $289.3 \mathrm{eV}$ were attributed to hydrocarbons and carbonate species [26] respectively while the signal at $287.2 \mathrm{eV}$ points toward the presence of carbonilic or amidic [27] carbon belongings to molecules with a biological origin. The two nitrogen bands, centred in a region typical of the negative ionization state of this element, were attributed to the amidic (399.6 eV) [27] and quaternary ammonium (402.0 eV) [28] nitrogen respectively. These evidences show the presence of biological molecules on the limestone surface.

No similar evidence was found by using conventional spectroscopic techniques (FT-IR), which shows the potentiality of the XPS approach.

\section{Secondary Ion Mass Spectrometry}

The basic feature of SIMS spectroscopy is the analysis of the $m / Z$ values of ionic fragments generated on the surface of a material bombarded with a primary ion beam [29]. The application of this surface technique is particularly useful not so much for its analytical implications as for the chemical information supplied $[30,31]$. From the various examples given we wish to concentrate on one which concerns the biological degradation of basalt materials, these being commonly used in church and cathedral construction in the Mediterranean area [32]. These materials are generally considered to be strongly resistant against the aggression of micro-organisms such as bacteria and fungi; whereas they differ from calcareous materials which, due to their intrinsically 

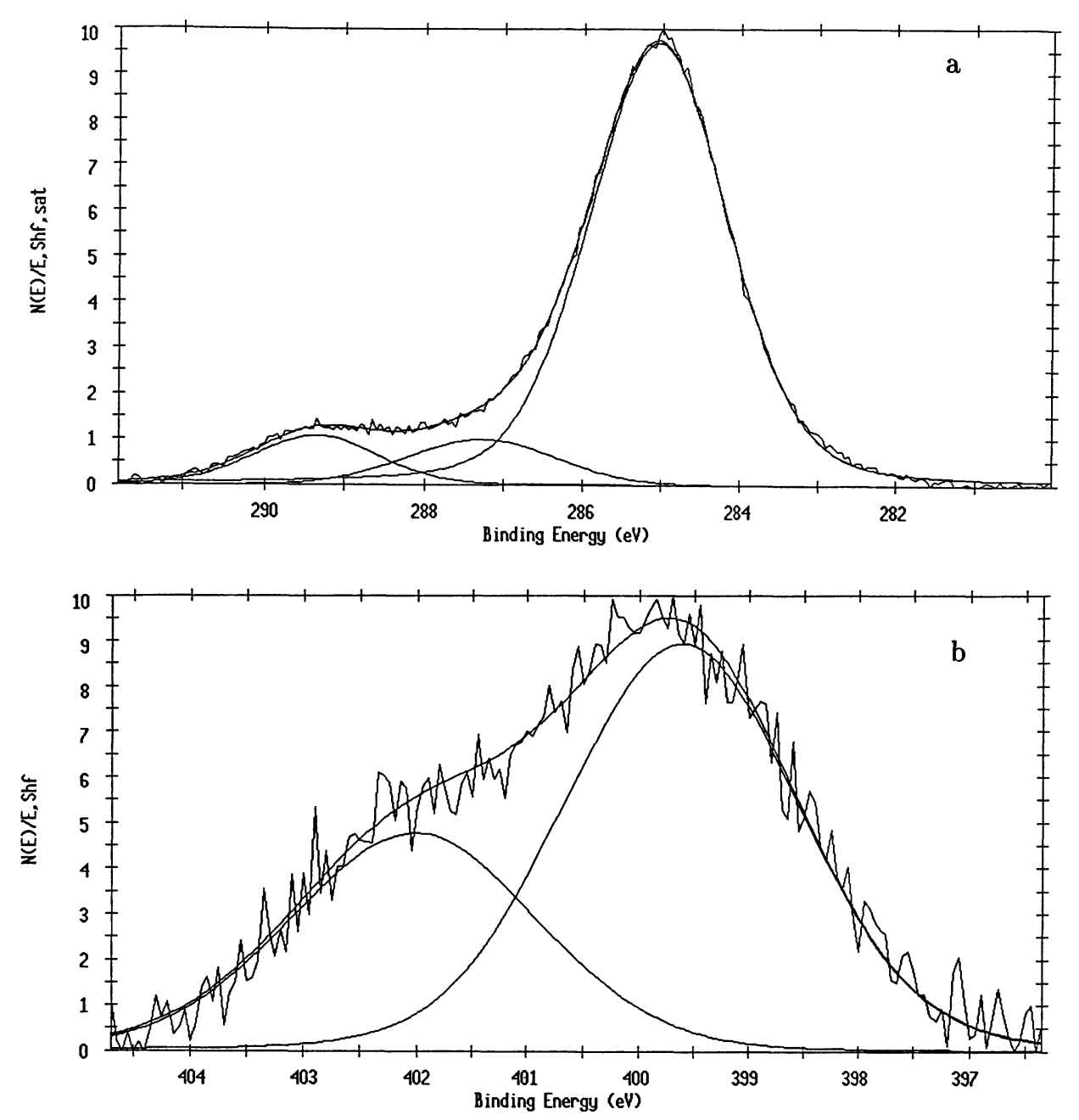

Fig. 7. - XPS spectra of the surface of the sample shown in Figure 1: a) carbon 1s region, b) nitrogen 1s region.

alkaline nature, are ease prey for the acid metabolites of biodeteriorating organisms [33]. Despite this, certain types of degradation in basalt materials appear to have involved a biological form of aggression [34]. In order to study this further, certain strains of bacteria (Penicillum Semplicissimum) were taken from the lava-stone of two monuments (the gothic church of S. Martino and the church of Santa Maria in Randazzo, Sicily) and these were then incubated with lava material. The SIMS technique immediately seemed ideal for checking on biological aggression which is generally an extremely slow process, since this technique works on the first few atomic monolayers of the material.

Figure 8 shows the SIMS signals corresponding to the ${ }^{28} \mathrm{SiO}^{+},{ }^{29} \mathrm{SiO}^{+}$and ${ }^{28} \mathrm{SiOH}^{+}$species obtained from the two samples incubated in system which were chemically identical but biologically different. The spectrum on the left comes from a sterile material while that on the right shows the presence of biodeteriorating agents. The steep increase in the ${ }^{28} \mathrm{SiOH}^{+}$species is clearly noticeable. This is an unequivocal indication of surface degradation caused by the hydrolysis of the 


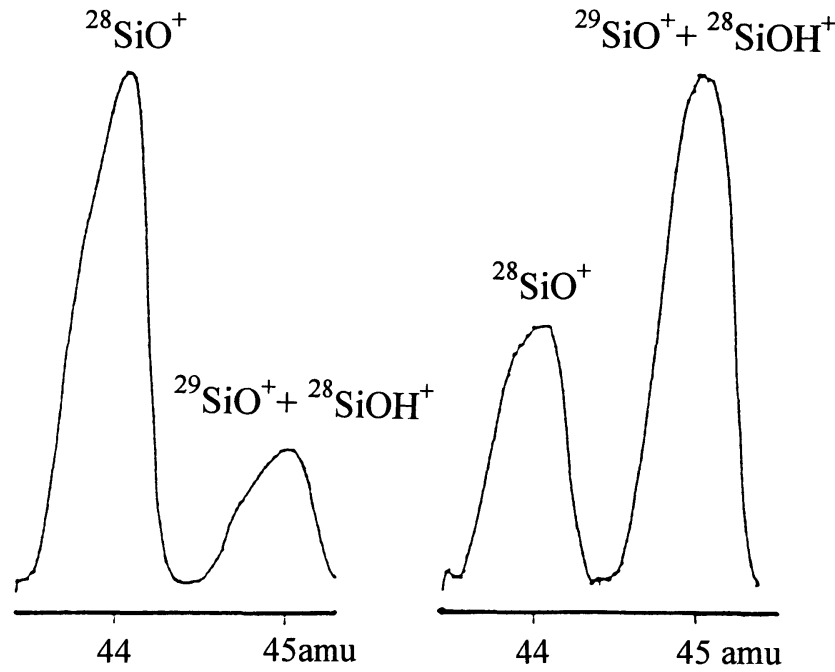

Fig. 8. - SIMS of basalts: signals corresponding to ${ }^{28} \mathrm{SiO}^{+},{ }^{29} \mathrm{SiO}^{+}$and ${ }^{28} \mathrm{SiOH}^{+}$before (on the left) and after (on the right) the biological treatment.

SiOM bonds with the formation of silica. Similar proof has never before been shown in surface experiments and this provides a whole new outlook in the field concerning the slow kinetics of surface aggression through biodeteriorating agents.

\section{Conclusion}

The range of information provided by the techniques outlined above is of considerable importance. It would appear that the characterization of materials used, the type of degradation sustained and the mechanisms activating this should be considered as being indispensable preliminary investigations prior to deciding strategies for conservation which aim, at least in part, to eliminate the causes of deterioration. It is also necessary to emphasize the fact that all of the complementary techniques mentioned can identify very small micrograins of material, even less than $1 \mu \mathrm{m}$ in size corresponding to $10^{-12}-10^{-13} \mathrm{~g}$, not easily detectable by microanálytical tests. These facilities, on the other hand, allow to work with extremely small quantities of material so that these investigations may be defined as microdestructive.

The microdestructive characteristic of the sampling appears to be of great relevance where the complexity and the heterogeneity of the artifact require a statistical set of samplings to obtain significative information. On the other hand should be outlined that, many times, the microdestructive approach does not have any alternative if a complete analytical and microtopographical description is requested.

These techniques may provide archeometric information as well. In many cases information regarding the primary materials and execution techniques used can be obtained, these being elements which often prove to be fundamental for establishing the time and location of an art-work with accuracy [31].

Finally, surface techniques would also seem to provide the best solution in the study of slow degradation processes, those that normally occur over hundreds of years. These techniques allow 
chemical information to be obtained for areas on the material-atmosphere interface and can reveal degradation processes in their initial steps while they are not detected by using conventional bulk techniques.

\section{References}

[1] Goldstein J.I., Newbury D.E., Echlin P., Joy D.C., Fiori C. and Lifshin E., Scanning Electron Microscopy and $\mathrm{X}$ ray Microanalysis (Plenum Press, New York, 1989).

[2] Cooke P.M., Anal. Chem. 66 (1994) 558R, and references therein.

[3] Goodhew P.J., Specimen Preparation in Materials Science, Practical Methods in Electron Microscopy, A.M. Glauert Ed. (Elsevier, 1973).

[4] Biscontin G., Fassina V., Maravelaki P. and Zendri E., Mat. Res. Soc. Symp. Proc. 185 (1991) 253.

[5] Berlasso M.T., Bruschi A., Longega G., Pagani T., Perusini T., Proietti A., Biscontin G., Repaci G., Maravelaki P., Zendri E., Galeazzo G., Spadea P., in Le Pietre nell'Architettura: Struttura e Superfici (Lib. Progetto Ed. Padova, 1991) p. 923.

[6] Yerrapragada S.S., Jaynes J.H., Chirra S.R. and Gauri K.L., Anal. Chem. 66 (1994) 655.

[7] I. C. R., DIMOS - Tecniche di Esecuzione e Materiali Costitutivi, 1, (1978).

[8] Ciliberto E., Fragalà I., Spoto G., Di Stefano C., Allen G.C., Anal. Chem 67 (1995) 249A.

[9] Owen J.V., Day T.E., Archaeometry 36 (1994) 217.

[10] Dziunikowski B., “Energy Dispersive X-Ray Fluorescence Analysis”, Comprehensive Analitical Chemistry, G. Svehla Ed. (Elsevier, 1989).

[11] Verità M., Basso R., Wypyski M.T., Koestler R.J, Archaeometry 36 (1994) 241.

[12] Török S.B., Van Grieken R.E., Anal. Chem. 66 (1994) 186R, and references therein.

[13] Mora P., Mora L., Philippot P., Conservation of Wall Paintings, (Butterworths, 1984).

[14] Seah M.P., Briggs D., Practical Surface Analysis, Vol.1: Auger and X-ray Photoelectron Spectroscopy, D. Briggs and M.P. Seah Eds. (John Wiley \& Sons Ltd., 1990).

[15] Cazaux J., Lehuede P., J. Electron. Spectrosc. Relat. Phenom. 59 (1992) 49.

[16] Le Gressus C., Blaise G., Analyt. Chim. Acta 297 (1994) 139.

[17] American Society for Testing and Materials, Surf. Interface Anal. 17 (1991) 893.

[18] McNeil R.J., Advanced in Chemistry Series 205 - Archaeological Chemistry III, J.B. Lambert Ed., (1984) 255.

[19] Seah M.P., Dench W.A., Surf. Interface Anal. 1 (1979) 2.

[20] Viefhaus H, Analyt. Chim. Acta 297 (1994) 43.

[21] Partridge A., Tatlock G.J., Surf. Interface Anal. 18 (1992) 713.

[22] Turner N.H., Schreifels J.A., Anal. Chem. 66 (1994) 163R, and references therein.

[23] Allen G.C., Ciliberto E., Ienco G., Younes C., Pinasco M., Stagno R., Spoto G., work in progress.

[24] Sabbatini L., Guascito R., Palmisano F., Rotunno T., Zambonin P.G., Sci. Technol. Cultural Heritage 3 (1994) 2.

[25] Volpin S., Bertoncello R., in Superfici dell'Architettura: le finiture, (Lib. Progetto Ed., Padova, 1990) p. 243.

[26] Christie A.B., Lee J., Sutherland I., Wells J.M., Appl. Surf. Sci 15 (1983) 224.

[27] Beamson G., Briggs D., High Resolution XPS of Organic Polymers, (John Wiley \& Sons Ltd., 1992).

[28] Burger K., Tschismarov F., Ebel H., J. Electron. Spectrosc. Relat. Phenom. 10 (1977) 461.

[29] Seah M.P., Briggs D., Practical Surface Analysis, Vol.2: Ion and Neutral Spectroscopy, D. Briggs and M.P. Seah Eds. (John Wiley \& Sons Ltd., 1992). 
[30] Secondary Ion Mass Spectrometry - SIMS VII, Proc. Seventh International Conference on Secondary Ion Mass Spectrometry, A. Benninghoven, C.A. Evans, K.D. McKeegan, H.A. Storms, H.W. Werner Eds. (John Wiley \& Sons, 1990).

[31] Ciliberto E., Fragalà I., Pennisi G., Spoto G., Sci. Technol. Cultural Heritage 3 (1994) 163.

[32] Lanza S., Sergi S., Stagno F., Triscari M., Grasso S., Gugliandolo C., Maugeri T., Ciliberto E., Fragalà I., Torrisi A., Proc. 7th International Congress on Deterioration and Conservation of Stone, Lisbon (1992) p. 471.

[33] Mariottini M., Laurenzi Tabasso M., Bianchetti P., Proc.: The Oxalate Films: Origin and Significance in the Conservation of Works of Art, Milano (1989) 53.

[34] Silverman M.P., Munoz E.F, Science 169 (1970) 985. 